\title{
Swap İşlemlerinin TMS, BOBİ FRS ve VUK Kapsamında Muhasebeleştirilmesi ve Vergilendirilmesi
}

\begin{abstract}
Adile AKTAR ${ }^{1}$
$\ddot{O} z$

Günümüz küresel rekabet ortamında hızlı değișim göstermekte olan ekonomik koșullar iṣletmelerin bir takım finansal risklerle karşı karşıya kalmalarına neden olmaktadır. Finansal risk, işletme varlıklarının değerlerinde ve beklenen getirilerinde azalışa, borçlarında ve faiz yüklerinde ise artışa sebebiyet verebilecek olumsuz finansal olaylardır. İșletmelerin bu risklerden korunabilmeleri ve faaliyet göstermekte oldukları sektörde rekabet güçlerini arttırabilmeleri gibi gereksinimleri dolayısıyla türev ürünleri kullanmaları zorunlu bir hal almışıı. Bu çalışmanın amacı; türev ürünler arasında yer alan, genel anlamda borçların değiş tokuşu anlamına gelen swap işlemlerinin TMS, BOBİ FRS ve VUK kapsamında değerlendirilerek, bu düzenlemeler açısından ortaya çıkan farklılıkları ve bu farklılıkların muhasebe uygulamalarına etkilerini ortaya koymaktır. Çalıșmada yöntem olarak çalışmanın konusuna uygun iki adet hipotetik işletme verisi kullanılmış, bu veriler kapsamında işletmelerin gerçekleştirdikleri faiz ve döviz swap işlemleri TMS, BOBİ FRS ve VUK kapsamında vergilendirilme ve muhasebeleştirilme boyutuyla ele alınmıştır. Sonuç olarak faiz ve döviz swaplarının farklilkları tespit edilmiş, muhasebe uygulamalarına etkileri örnek uygulamalarla ortaya konulmuștur.
\end{abstract}

Anabtar Kelimeler: Türev ürünler, Swap İşlemleri, Muhasebeleştirme ve Vergilendirme

\section{Accounting and Taxation of Swap Procedures in the Scope of TAS, BOBI FRS and TPL}

\begin{abstract}
The economic conditions that are changing rapidly in today's global competition environment cause companies to face many financial risks. Financial risk is a negative financial event that may lead to a decrease in the values and expected returns of the companies assets and increase in the debts and interest loads. Companies have to use derivative instruments due to their requirements such as protection against these risks and increasing their competitiveness in the sector in which they operate. The aim of this study is to investigate the swaps which are among the derivative instruments and which mean the exchange of debts in general. Taxation and accounting for swaps are included in the scope of TAS, BOBI FRS and TPL. As a result, suggestions were made within the framework of the example given.
\end{abstract}

Key Words: Derivative instruments, Swap Transactions, Taxation and Accounting

Atıf İçin / Please Cite As:

Aktar, A. (2022). Swap işlemlerinin TMS, BOBİ FRS ve VUK kapsamında muhasebeleştirilmesi ve vergilendirilmesi. Manas Sosyal Araștırmalar Dergisi, 11(1), 342-354.

Geliş Tarihi / Received Date: 11.02.2021

Kabul Tarihi / Accepted Date: 8.07.2021

\footnotetext{
1 Öğr. Gör. - Türkiye-Isparta Uygulamalı Bilimler Üniversitesi Gelendost Meslek Yüksekokulu, adileaktar@isparta.edu.tr

(D) ORCID: 0000-0001-7632-4552
} 


\section{Giriş}

Günümüzde çok hızlı bir değişim içerisinde bulunan ekonomik koşullar, işletmeleri maruz kaldıkları riskler karşısında daha fazla önlem almaya zorlamaktadır. Bu durum işletmelerin türev ürünleri kullanımını daha yaygın bir hale getirmektedir. Türev ürünler fiyatlanı diğer ürünlerin fiyatlarına bağlı olarak değişen, belli bir vade içerisinde ve sonundaki değeri sözleşmeye konu edilen varlığa göre tespit edilen araçlardır. İşletmeler, türev ürünlerden riskten korunmak için yararlanmanın yanı sıra ticari kar sağlama amacı ile de yararlanabilmektedirler. Finansal piyasalarda meydana gelen bütün bu gelişmeler, muhasebe ve finansal raporlama sistemlerinde de bir takım gelişmeler yapılmasına ilişkin çalışmaların başlatılmasına sebep olmuştur.

Türev ürünler aracıllğıyla gerçekleştirilen işlemlerin hacminde meydana gelen artış, bu araçlar aracıllı̆ıyla gerçekleştirilen işlemlerin finansal etkilerinin finansal tablolara yansıtılmasına ilişkin bir takım sorunların gündeme gelmesine neden olmuştur. Türev ürünlerle gerçekleştirilen işlemlerin kaydedilmesi, değerlendirilmesi ve raporlanmasına ilişkin bütün bu sorunların çözüme kavuşturularak, uygulamada bütünlügün sağlanması amacına yönelik olarak Uluslararası Muhasebe Standartları Kurulu (IASB) bazı çalışmalar yürütmüş ve bu çalışmalar sonucunda türev araçların muhasebeleştirilmesi hususunda 32 ve 39 numaralı Uluslararası Muhasebe Standartları ve 7 numaralı Uluslararası Finansal Raporlama Standardı yürürlüğe girmiştir. Ülkemizde ise Türkiye Muhasebe Standartları Kurulu'nun (TMSK) yayımlamış olduğu standartlar bağlamında birtakım yasal düzenlemeler yürürlüğe girmiştir. Günümüzde ise standartları yayınlama ve düzenleme yetkisi Kamu Gözetim Kurumu'na aittir.

Bu çalışmada ülkemizde en çok kullanılan türev ürünler arasında yer alan swap işlemleri ve özelliklerine değinilmiş, swap işlemlerinin taraflarından bahsedilmiş, swap türleri üzerinde durulmuştur. Ayrıca swap işlemlerinin vergilendirilmesi ve muhasebeleştirilmesi hususları TMS 32 Finansal Araçlar: Sunum, TMS 39 Finansal Araçlar: Muhasebeleştirme ve Ölçme, BOBİ FRS Bölüm 9: Finansal Araçlar ve Özkaynaklar açısından incelenmiştir. Swap işlemlerinin vergi mevzuatımız karşısındaki durumu ise, Vergi Usul Kanunu, Kurumlar Vergisi Kanunu, Gelir Vergisi Kanunu, Katma Değer Vergisi Kanunu, Banka Sigorta Muamele Vergisi Kanunu ve Damga Vergisi Kanunu özelinde ele alınarak incelenmiştir.

\section{Swap İşlemlerine İlişkin Kavramsal Çerçeve}

İngilizce kökenli olan swap kelimesi değiştirme, takas ve kaydırma anlamları taşımaktadır (Ersan, 1998, s.166). Swap uygulaması döviz kurları ve faiz oranlarındaki dalgalanmalardan kaynaklı olan risklerin azaltılması amacıyla geliştirilmiş olan bir tekniktir (Nurcan, 2005, s. 23). Swap literatürde kısaca, farklı iki para biriminden olan tutarın birbiriyle değiştirilmesi, takas edilmesi olarak tanımlanmaktadır (Özalp, 2013, s. 4).

Swap ilk olarak 1923 senesinde Avusturya Merkez Bankasının spot pazarda GBP karşllı̆̆ında yerli paranın satılarak vadeli geri satın alımının gerçekleştirilmesinde kullanılmıştır. 1981 senesinin Ağustos ayında Dünya Bankası ile IBM arasında gerçekleştirilmiş olan döviz kuru swapı işlemiyle swap piyasası geçerliliğini bütün dünyaya kanıtlamıştır (Flavell, 2002, s. 9). Bu bağlamda swap işlemi daha önceden belirlenmiş olan bir sistem içinde, finansal bir varlık sebebiyle meydana gelen ileri bir tarihteki nakit akımlarının değiştirilmesi amacıyla iki taraf arasında gerçekleştirilen bir sözleşmedir (Ceylan, 2002, s. 233).

Swapta değişime konu olan ödemeler; anapara faizi ya da hem faiz hem de ana para ödemesi olabilmektedir (Kendirli ve Satır, 1998, s. 104). Başka bir ifade ile swap; döviz kurlanı ile faiz oranı risklerine karşı geliştirilmiş olan, fon kullanıcılarının farklı piyasalarda bulunan fonlara erişimini kolaylaştıran, riskleri azaltan ve sabit faizli olan bir fonun değişken faizli olan bir fona dönüştürülmesi imkanı tanıyan finansal bir yöntemdir (Bal, 2001, s.148). Swap işlemlerinin temel amacı, finansal işlemlerin maliyetlerini ve risklerini azaltabilmek için swap işlemine katılan taraflara karşılıklı fayda sağlamaktır (Önce, 1995, s. 23). Swap' in özellikle günümüzde sıkça uygulanmakta olan bir diğer amacıysa; faiz oranı, döviz kuru gibi değişimlerden kaynaklanmakta olan risklere karşı sözleşme taraflarına güvence sağlamasıdır (Örten ve Örten, 2001, s. 311). Özetle swap sözleşmeleri, fon kullanıcılarına farklı piyasalardaki avantajlardan yararlanarak riski minimize etme, uygun fonlara kolayca erişebilme gibi avantajlar sağlamaktadır (Arıkan, 2000, s. 18). 


\section{Swap İşleminin Tarafları}

Swap işleminin tarafları faiz oranlarıyla döviz piyasalarında meydana gelen değişimlerden faydalanabilmek amacıyla bu işlemi gerçekleştirmektedirler (Önce, 1995, s. 23). Swap işleminin tarafları; aracılar ve son kullanıcılar olarak iki gruba ayrllmaktadır (Aygören ve Kurtcebe, 2019, s.6). Son kullanıcılar ekonomik sebeplerle döviz kuru riskiyle faiz oranını azaltmak için swap işlemine katılırken, aracılar ise komisyon almak ve kazanç sağlamak amacıyla swap işlemlerine taraf olmaktadırlar (Akay, 2002, s. 34).

\section{Swap Türleri}

En yaygın kullanılan swap sözleşmeleri faiz ve para swapı iken, uygulamada mal swapları, swap opsiyonları, artan swap, azalan swap, kuponsuz swap, varlık swapları gibi swap çeşitleri de bulunmaktadır (Akay, 2002, s. 34; Özdemirci, 2000; s. 139; Öztürk, 2001, s. 122). Bu kısımda en yaygin olarak kullanılan swap türleri olan para swapı ve faiz swapı türlerine değinilecektir.

\section{Para Swap1 (Döviz Kuru Swap1, Döviz Swapı)}

Para Swap1, belli bir dönemde iki ayrı para biriminden olan anapara miktarlarının daha önceki bir tarihte belirlenen bir kur üzerinden değiş-tokuşunun yapılması, belirli olan bu dönem içinde tarafların kullanmıs oldukları anaparaların faizlerini karşı tarafa ödemeleri ve yeniden değiştirmeleri işlemine verilen isimdir (Cormick, 1993, s. 17). Para swapı işlemi; farklı para birimlerinden anaparaların değiştirilmesi, tarafların kullanmış oldukları anaparaların faizlerinin değiş-tokuş edilmesi ve tarafların anaparalarını vade bittiğinde karşlıklı olarak iade etmeleri olmak üzere üç aşamadan oluşur (Toroslu, 2000, s. 130).

\section{Faiz Swap1}

Faiz swapı; çeşitli borçlanma kaynaklarıyla, benzer vadelerde ve aynı tutarlarda anapara borçlanmış durumda olan birbirinden bağımsız iki farklı tarafın, faiz yükümlülüklerini bir banka aracıllğıyla karşılıklı olarak birbirlerine devretmeleri ile gerçekleşen swap işlemidir (Önce, 1995, s. 26). Başka bir ifadeyle faiz swapı; sözleşme süresi boyunca, iki tarafın da birbirlerine, aynı para cinsinden, aynı miktardaki anaparaya, sabit veya değişken faiz oranlarının uygulanması ile hesaplanan meblağların, karşılıklı olarak, aynı para birimiyle ödenmesini taahhüt etmiş oldukları anlaşmadır (Keskin, 2008, s. 78).

\section{Türkiye Muhasebe Standartları Kapsamında Swap İşlemleri}

\section{TMS 32 Finansal Araçlar: Sunum Standardı Bağlamında Swap İşlemleri}

TMS 32 kapsamında finansal araç; bir işletmenin sahip olduğu finansal varlığıyla başka bir işletmenin finansal borçlarında veya öz kaynağa dayalı olan finansal araçlarında artış olmasına sebebiyet veren herhangi bir sözleşme olarak nitelendirilmektedir (Özerhan ve Yanık, 2012, s. 164). TMS 32'nin amac1, finansal araçların özkaynak ya da borç şeklinde sunulmaları ve finansal varlıklarla borçların netleştirilme ilkelerin belirlenmesidir. Bu bağlamda finansal tablo kullanıcılarının, finansal ürünlerin işletmelerin finansal durumlarındaki, performanslarındaki ve nakit akışlarındaki olası etkilerini daha iyi idrak etmelerine yardımcı olunması amaçlanmaktadır (Ceran ve Öz, 2014, s. 229). Bu standart gereğince finansal araçlar; finansal borç ve finansal varlık olarak iki gruba ayrlırken, türev ürünlere de nitelikleri kapsamında yapılan sınıflandırma bağlamında finansal varlık veya finansal borçlar arasında yer verilmiştir (Bal ve Öztürk, 2013, s. 126).

TMS 32 standardında yer almakta olan esaslar, "IAS/TMS 39 Finansal Araçlar: Muhasebeleştirme ve Ölçme" standardında bulunan finansal varlıklarla borçların muhasebeleştirilmesi ve ölçülmesine dair ilkelerle bunlara ilişkin bilgilerin kamuoyuna sunulmasina yönelik olarak "TFRS 7 Finansal Araçlar: Açıklamalar" Standardında bulunan ilkeleri tamamlamaktadır. TMS 32 standardının temel ilkeleri ile TMS 39 Finansal Araçlar: Muhasebeleştirme ve Ölçme standardının temel ilkelerinin paralellik gösterdiği ifade edilmektedir (Örten, Kaval ve Karapınar, 2012, s. 470).

\section{TMS 39 Finansal Araçlar: Muhasebeleştirme ve Ölçme Standardı Bağlamında Swap İşlemleri}

2006'da Resmi Gazetede yayınlanmış olan TMS 39 standardı "Bir işletmenin beklenmekte olan alım, satım ya da kullanım ihtiyaçları kapsamında finansal nitelikte olmayan bir kalemi teslim etmek ya da teslim almak amacı ile düzenlenerek elde tutulmaya devam edilenler hariç, nakitle ya da farklı bir finansal araçla veya sözleşmeleri finansal araçmış gibi değerlendirerek finansal araçların karşılıklı bir şekilde birbirleri ile takas edilmeleriyle net olarak ödenebilen finansal nitelikli olmayan kalemlerin alım-satımına dair sözleşmelere uygulanır.” şeklinde ifade edilmiştir (Özerhan ve Yanık, 2012, s. 163). TMS 39 standardının 
bütün işletmeler tarafından birtakım araçlar dışındaki bütün finansal araçlara uygulandığı belirtilmiştir. Bu standardın kapsamı dışında olan araçlar şunlardır (Sağlam, Şengel ve Öztürk, 2009, s. 991):

- İş ortaklıklarındaki paylar, bağlı ortaklıklar ile iştirakler,

- Çalışanlara ilişkin varlık, hak ve yükümlülükler,

- Sigorta sözleşmeleri,

- Kiralama işlemleri,

- İşletme birleşmelerinde işletmeyi satın alanın üstleneceği yükümlülükler,

- Hisse bazlı ödemelerdir.

TMS 39 standardının amacı; finansal nitelikli borçların, varlıkların ve finansal nitelikli olmayan kalemlerin alım-satımını içeren sözleşmelerin muhasebeleștirilmesine ve ölçülmesine dair ilkelerin belirlenmesidir (Mısırlığlu, 2008, s. 70). Finansal araçlara dair bilgilerin sunulmasına ilişkin hükümler “TMS 32 Finansal Araçlar: Sunum” standardı kapsamında ele alınırken, finansal araçlara dair kamuoyuna yapılacak açıklamalara ilişkin hükümler ise "TFRS 7 Finansal Araçlar: Açılamalar" standardı kapsamında ele alınmaktadır (IAS/TMS 39 md.1-2).

\section{BOBİ FRS Kapsaminda Swap İşlemleri}

\section{Bölüm 9: Finansal Araçlar ve Özkaynaklar Bağlamında Swap İşlemleri}

BOBİ FRS'ye göre finansal varlık ve borçlar şu şekilde sınıflandırılmaktadır (Kıymetli Şen ve Özbirecikli, 2018, s. 469):

- Alacak ve borçlar,

- Borçlanma araçları,

- Özkaynak araçlarındaki yatırımlar,

- Diğer finansal araçlardır.

$\mathrm{Bu}$ sınıflandırma bağlamında incelendiğinde swap işlemleri diğer finansal araçlar kapsamında yer almaktadır. BOBİ FRS'ye göre diğer finansal araçlar, forward, future, swap, opsiyon gibi türev finansal araçlar ve varlı̆̆a dayalı menkul kıymetler; ilk kayıtta ve daha sonraki süreçlerde gerçeğe uygun değeri ile ölçülmektedir (Kamu Gözetim Kurumu, 2017). Diğer finansal araçlar arasında yer alıp nakitle yerine getirilemeyen ya da tahhhütler yerine getirildiğinde borçlanma aracı kapsamına girmekte olan kredi alımlarına ilisskin olan taahhütler, maliyet bedeli ile değerlenmektedir. Bu tarz taahhütler ilk kayıt esnasında, işlem maliyetlerinin de dahil edilmesiyle işlem fiyatları üzerinden ölçülmektedir. Daha sonra yapılacak ölçümlerde eğer varsa değer düşüklügü zararları da hesaplanacak, bu tutar maliyet değerinden düşülecektir (Kamu Gözetim Kurumu, 2017). Bu bağlamda BOBİ FRS ile TMS/TFRS ilkeleri türev finansal araçların değerlemesi bakımından uyumludur.

\section{Swap İşlemlerinin Türk Vergi Mevzuatı Karşısındaki Durumu}

Swap işlemleri kapsamında bir takım vergisel yükümlülükler meydana gelmektedir. Ancak, ülkemizde bu konuya ilişkin yasal mevzuatın yetersiz olması sebebiyle swap işlemlerinin vergi peçelemesi yapmak amacıyla kullanıldığı görülmektedir.

\section{Swap İşlemlerinin Vergi Usul Kanunu Karşısındaki Durumu}

Bankaların vadeli döviz alım satım genel sözleşmeleriyle vade tarihinde uygulamakta oldukları kurun, ilgili gündeki cari kurun üzerinde olması durumunda ve bu kapsamda faiz ödemesinin kur farkı adı altında gizleme işleminin yapılması durumunda, bir takım vergi yükümlülüklerinden kurtulabilmek için yapılan bir muvazaalı işlem olarak kabul edilebilir (Öz ve Pekşen, 2010, s. 7). Yapılan bu işlem uygulamada vergi peçelemesine sebebiyet vermektedir. Menkul kıymet niteliği taşımayan bu tarz sözleşmelerde kar ya da zarar işlemlerin gerçekleşmiş olduğu ve elde edilmiş olduğu vade tarihinde gerçekleşmektedir. Bu sebeple de swap sözleşmeleri dönem sonu geldiğinde herhangi bir değerleme işlemine tabi tutulmamaktadır. Bahsi geçen bu işlemler muhasebe uygulamaları açısından değerlendirildiğinde nazım hesaplarda izlenmesi gerekli olan bilanço dışı işlemler olarak nitelendirilmektedir. Bu işlemler sonucunda ortaya çıkan kur farkı gelir ve giderleri ile faiz gelir ve giderlerinin ne şekilde değerlendirilmesi gerektiği tartışma yaratmaktadır. Ülkemizde risk yönetim muhasebesinin yaygınlaşmamış olması nedeniyle ortaya çıkan spekülatif işlemlerle hedging amacıyla gerçekleştirilen işlemlerin birbirinden ayrıştırılması da pek mümkün olmamaktadır. 
Halihazırda uygulamada olan vergi kanunlarımızın da böylesi bir ayrıma dayalı olan farklı vergileme rejimlerine imkan vermediği bilinen bir gerçektir (Öz ve Pekşen, 2010, s. 8).

\section{Swap işlemlerinin Gelir ve Kurumlar Vergisi Karşısındaki Durumu}

Gelir Vergisi Kanununun 1. maddesi uyarınca "Gerçek kişiliğe haiz olanların elde ettikleri gelirler gelir vergisine tâbidir. Gelir, gerçek kişiliğe haiz olanların bir takvim yılı içerisinde elde etmiş oldukları kazanç ve iratların safi tutarıdır." hükümleri yer almaktadır. Bahsi geçen kanunun 2. maddesindeyse geliri meydana getiren unsurlar tek tek sayılmaktadır (GVK, Md.1-2). Bu bağlamda sağlanan gelir ticari bir işletme tarafindan elde ediliyorsa, kaynağına bakılmaksızın ticari işletmeler tarafindan elde edilen kazanç olarak tanımlanmaktadır. Ticari işletme bünyesinde elde edilmiş olan gelirler ise Gelir Vergisi Kanununun 2. maddesinde sayllmakta olan gelir unsurlarından hangisinin kapsamında yer alıyorsa o kapsamda vergilendirilmektedir (Aydın, 2002, s. 220).

Ticari faaliyet kapsamının dışında gerçekleştirilen, yani gelir vergisi mükellefi olan gerçek kişilerce swap işlemleri ile elde edilen gelirlerin vergilendirilmesi hususunda Türk vergi mevzuatında herhangi bir düzenleme yer almamaktadır. $\mathrm{Bu}$ sebeple, swap işlemlerinden elde edilen gelirleri net bir şekilde vergilendirebilecek nitelikte bir gelir unsuru kapsamında değerlendirmek kanunilik ilkesi gereğince mümkün olmamaktadır (Öz ve Pekşen, 2010, s. 8). Gelir Vergisi Kanununun 75. maddesi uyarınca bu husus "Sahibi tarafindan ticari, zirai veya mesleki faaliyet haricinde nakdi sermayeye ya da parayla temsil edilmekte olan değerlerden müteşekkil sermaye sebebiyle elde edilen faiz, kar payı, kira ve benzer iratlar menkul sermaye iradıdır." şeklinde hüküm altına alınmaktadır (GVK, Md.75).

Swap işlemiyle sağlanan kazançlar da aynı maddede belirtilmekte olduğu gibi nakdi sermaye ile elde edilmektedir. Diğer yandan swap işlemlerinin ticari, zirai ya da mesleki faaliyet kapsamı dişında bireysel yatırım şeklinde gerçekleştirilmesi de mümkün olmaktadır. Sayılan iki özelliği bünyesinde barındırması tartışmaya konu olmasının yanında menkul sermaye iradı olarak ta değerlendirilebilmektedir. Çünkü swap işlemlerinden sağlanan gelir özünde faiz ve kar payı olarak nitelendirilmekte ve bu sebeple de menkul sermaye iradı olarak değerlendirilmesi gerekmektedir. Danıştayın verdiği kararlar incelendiğinde swap işlemlerinden elde edilen kazancın faiz olarak değil de kur farkı olarak nitelendirildiği görülmektedir. Dolayısıyla sayılan işlemlerin Gelir Vergisi stopajına tabi tutulmasına da imkan tanımamış olmaktadır (Aydin, 2002, s. 221).

Kurumlar vergisi mükelleflerince swap işlemlerinden elde edilen kazançlar ise hiçbir sınırlamaya tabi olmadan ve hiç bir vergi kolayllğı sağlanmadan kurum kazancına dahil edilmekte ve vergiye tabi tutulmaktadır. Bu işlemlerin muvazaalı işlemler şeklinde gerçekleştirilmesi halinde, 5520 Sayılı Kurumlar Vergisi Kanununun 12. maddesinde düzenlenmiş olan örtülü sermayeye ilişkin hükümler uygulanmaktadır.

\section{Swap işlemlerinin Katma Değer Vergisi Karşısındaki Durumu}

3065 Sayll Katma Değer Vergisi Kanununun 1. maddesi uyarınca, Türkiye'de ticari faaliyet bağlamında gerçekleştirilen teslimlerin ve hizmetlerin katma değer vergisine tabi tutulacağı hüküm altına alınmıştır. Bu sebeple ticari faaliyet kapsamında gerçekleştirilen türev piyasasına ilişskin işlemler katma değer vergisine tabi olmaktadır (Demir, 2000, s. 152). Diğer yandan bahsi geçen kanunun 17/4-g maddesi gereği döviz, külçe altın, hisse senedi, tahvil ve para teslimleri Katma Değer Vergisinden istisna edilmektedir. Bu bağlamda bahsi geçen ürünlerin finansal türev ürünlerine bağlı olan teslimleri de Katma Değer Vergisinden istisna kabul edilmektedir (Öz ve Pekşen, 2010, s. 10).

\section{Swap işlemlerinin Damga Vergisi Karşısındaki Durumu}

Damga vergisi taraflar arasında gerçekleştirilen hukuki nitelikli işlemlerin tesis edilmesini sağlayan ve bu işlemlere resmiyet kazandıran kağıtların vergilendirilmesini amaçlayan bir vergi türü olarak ön plana çıkmaktadır. Damga vergisinin konusuna bakıldığında ise, kağıda bağlı sözleşmelerin bu kapsamda yer aldıkları görülmektedir. Bu bağlamda bahsi geçen sözleşmelerin imzalanması ya da sözleşmelerde imza niteliğinde bir işaretin bulunması durumunda Damga Vergisi yükümlülüğü doğmaktadır (Özdemirci, 2000, s. 134).

Swap işlemleri de yazılı bir sözleşme ile gerçekleştirilmektedir. Swap işlemlerinin tarafları bu sözleşmeyle ödemelerini önceden belirlemiş oldukları esaslar ve kurallar çerçevesinde değiştirmektedirler. Fakat 2499 sayılı SPK Kanunun 40. maddesinde borsası kurulmakta olan ve borsada işlem görmekte olan türev araçların damga vergisinden istisna kabul edilmesinden dolayı swap işlemlerine ilişkin sözleşmeler damga vergisinden müstesna kabul edilmektedir (Öz ve Pekşen, 2010, s.10). 


\section{Swap İşlemlerinin Banka Sigorta Muamele Vergisi (BSMV) Karşısındaki Durumu}

6802 sayılı Gider Vergileri Kanununun 3297 sayılı Kanunla değişik 28. Maddesi uyarınca "Banka şirketlerinin ve sigorta şirketlerinin 10/6/1985 tarihli ve 3226 sayllı Finansal Kiralama Kanununa göre yapmakta oldukları işlemler hariç olmak kaydıyla, yapmış oldukları tüm muameleler sebebiyle kendi lehlerine nakden ya da hesaben almış oldukları paralar Banka ve Sigorta Muameleleri Vergisine tabidir." hükmü bulunmaktadır (Gider Vergisi Kanunu, Md. 28). Bahsi geçen kanunun 30. maddesi uyarnnca BSMV'ne göre bankaların, bankerlerin ve sigorta şirketlerinin mükellef oldukları belirtilmektedir. Ayrıca, aynı kanunun 29. maddesinin "p" bendinde, arbitraj muameleleri ile bu muameleler sonucunda lehte elde edilen paraların bahsi geçen vergiden istisna oldukları bildirilmiştir (Gider Vergisi Kanunu, Md. 30).

Yapılan açıklamalar bağlamında, swap işlemlerinin arbitraj işlemleriyle aynı nitelikte olduğu; dolayısı ile 6802 sayll Kanunun 29-p maddesi hükmü gereğince BSMV'den istisna olması gerektiğini belirten görüşler bulunmaktadır. Ayrıca swap işlemlerinin arbitraj muamelelerinden farklı niteliklere sahip bir finansal niteliği taşıdığı ve bu sebeple BSMV'ne tabi tutulması gerektiğini belirtenler de bulunmaktadır (Kaya, 2002, s. 119).

\section{Yöntem}

Swap işlemlerinin muhasebeleștirilmesi hususu, döviz swaplarının muhasebeleştirilmesi ve faiz swaplarının muhasebeleştirilmesi bağlamında farklı örnek uygulamalar üzerinden açıklanmıştır. Bu çalışmadaki örnek uygulamalar Canan Can'ın (2015) Enerji Piyasalarında Türev Araçlar ve Muhasebesi isimli çalışmasında yer alan örnek uygulamalardan uyarlanmıstır.

\section{Döviz Swaplarının Muhasebeleştirilmesine İlişkin Örnek Uygulama}

AA Bankasının 01/06/202X tarihinde 200.000 €’luk bir ödemesi bulunmaktadır. Bankanın aynı tarihte bu ödemeyi yapabileceği miktarda $€$ varllğı bulunmamaktadır. AA Bankası ödemeyi yapabilmek için elindeki \$ları satarak ihtiyacı olan €’yu alma imkanı bulunmasına rağmen, \$'in gelecekte € karşısında değer kazanacağını ve gelecekte $€$ tahsilatı olacağını öngörerek, elinde bulunan dövizi satmayıp, farklı bir bankayla üç ay vadeli olan bir swap sözleşmesi imzalamıştır. İmzalanan sözleşmeye uyarınca, AA Bankası karşı tarafa, $\$ / €=1,20$ paritesi üzerinden (spot kur) $€$ alarak $\$$ verecek, $30 / 08 / 202 X$ olan vade tarihinde ters yönlü değişim paritesi (forward kur) ise $\$ / €=1,10$ olarak gerçekleşecektir.

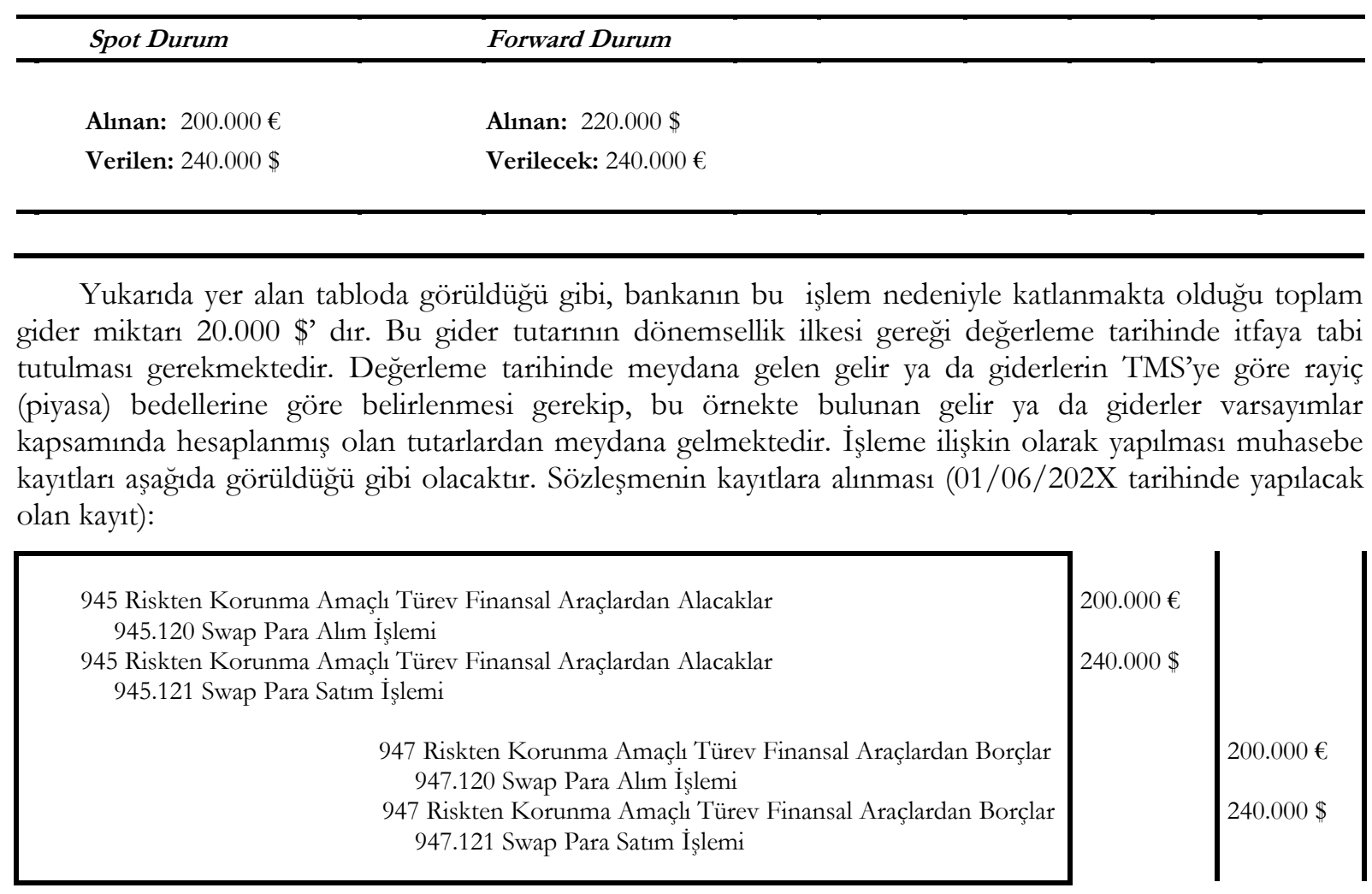




\section{AKTAR}

Uygulamada bazı bankalar bu tarz işlemleri gerçekleştirirken spot için de nazım kayıt kullanmaktadır. Alacak, işlemin gerçekleşmiş olduğu anda yani değişimin ilgili hesaplara alınması sonrasında yapılacak bu bir kaydın izleme ya da değerleme açısından hiçbir faydası bulunmaması sebebiyle bilanço dışı hesaplara yalnızca işlemin forward kısmını oluşturmakta olan taahhüde ilişkin kaydın yapılması yeterli olacaktır.

Alınan ve verilen paraların ilgili hesaplara alınması (01/06/202X tarihinde yapılacak olan kayıt):

\begin{tabular}{|c|c|c|}
\hline $\begin{array}{l}\text { 391 Muhtelif Borçlar } \\
\text { 391.05 Türev Finansal Araçlardan Borçlar }\end{array}$ & $200.000 €$ & $200.000 €$ \\
\hline $\begin{array}{l}279 \text { Muhtelif Alacaklar } \\
279.05 \text { Türev Finansal.Araçlardan Alacaklar }\end{array}$ & $240.000 \$$ & \\
\hline 025 Yurtdışı Bankalar & & $240.000 \$$ \\
\hline
\end{tabular}

Yukanıda yapılan kayıttan da anlaşıldığı gibi, gerçekleştirilen işlemden kaynaklı olan toplam gider 279 numaralı hesaba kaydedilmiș ve aktifleştirilmiştir. Peșin ödenen gider niteliğinde olan bu tutarın işlemin gerçekleşmiş olduğu tarihte 281-BORÇLU GEÇİCİ HESAPLAR altında yer almakta olan 281.01 numaralı Peşin Ödenmiş Giderler hesabına kaydedilebilir. Değerleme tarihinde, aktifleştirilmiş olan toplam giderin ilgili döneme aktarımı yapılan kısmının bahsi geçen hesaptan alınarak dönem giderlerine aktarılması gerekir.

Değerleme kayıtları;

Haziran 202X ay sonunda piyasa değerine göre hesaplanmakta olan gider reeskont tutarının 2000 \$ ve döviz kurunun $1 \$=2,6$ TL olduğu kabul edilmiştir.

30/06/202X tarihinde yapilacak kayit:

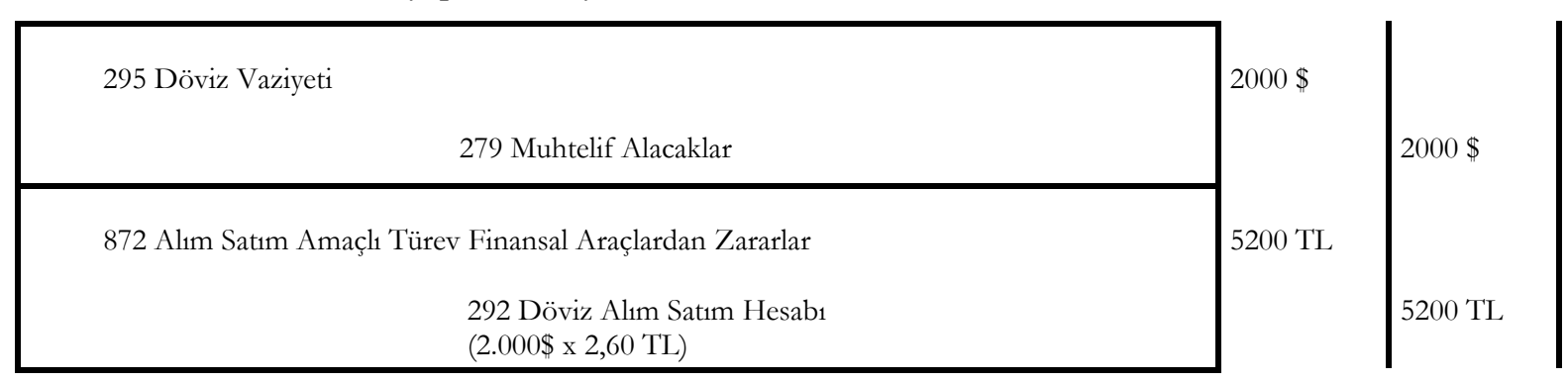

Hesaplama açısından kolaylık sağlaması amacı ile ara dönemlerde bu şekilde muhasebeleştirilmekte olan reeskontların, ertesi iş gününde iptal işleminin gerçekleştirilmesi gerekir.

Vade tarihinde (30/06/202X) yapılması gereken kayıtlar ise aşağıdaki görüldüğ̈ gibi olmalıdır.

\begin{tabular}{|c|c|c|}
\hline $\begin{array}{l}391 \text { Muhtelif Borçlar } \\
391.05 \text { Türev Finansal Araçlardan Borçlar } \\
\qquad 025 \text { Yurtdışı Bankalar }\end{array}$ & $200.000 €$ & $200.000 €$ \\
\hline $\begin{array}{l}\text { 279 Muhtelif Alacaklar } \\
279.05 \text { Türev Finansal Araçlardan Alacaklar }\end{array}$ & $\begin{array}{l}220.000 \$ \\
20.000 \$\end{array}$ & $240.000 \$$ \\
\hline $\begin{array}{l}872 \text { Alım Satım Amaçlı Türev Finansal Araçlardan Zararlar } \\
\qquad \begin{array}{l}\text { 294 Döviz A/S Hesabı } \\
\text { (20.000\$ x 2,70 TL) }\end{array}\end{array}$ & $54.000 \mathrm{TL}$ & $54.000 \mathrm{TL}$ \\
\hline
\end{tabular}


Not: Vade tarihinde döviz kurunun $1 \$=2,70$ TL olduğu varsayılmaktadır.

Sözleşmeye ilişkin taahhüdün kapatılması;

947 Risk. Korunma Amaçlı Türev Finansal Araçlardan Borçlar

947.120 Swap Para Alım İşlemi

947 Riskten Korunma Amaçlı Türev Finansal Araçlardan Borçlar 947.121 Swap Para Satım İşlemi

şeklinde muhasebeleştirilir.

\section{Faiz Swaplarının Muhasebeleştirilmesine İlişkin Örnek Uygulama}

BB Bankası 15/01/202X tarihinde ABC Bankasından LIBOR+\%1 değişken faizli ve altı ay vadeli olan 2.000.000 \$ tutarında kredi almıştır. Banka faiz oranlarında olması muhtemel dalgalanmalardan korunma amacı ile aynı tarihte DEF Bankası ile 2.000.000 \$ nominal değeri olan ve altı ay vadeli faiz swap1 sözleşmesi imzalamıştır. Sözleşme uyarınca BB Bankası DEF Bankasına \%3,25 sabit faiz ödemesi gerçekleştirecek ve buna karşılık olarak DEF Bankasından LIBOR $+\% 0,25$ faiz tahsilatı gerçekleştirecektir. Faiz ödemeleri ise vade tarihinde gerçekleştirilecektir. Sözleşme süresi boyunca gerçekleşmiş olan faiz oranları ve döviz kurları aşağıdaki tabloda görüldüğü gibidir:

\begin{tabular}{lll}
\hline Tarih & Libor (\%) & Kur $(\boldsymbol{T L})$ \\
\hline & & \\
$15 / 03 / 202 \mathrm{X}$ & 3,25 & 2,50 \\
$31 / 03 / 202 \mathrm{X}$ & 3,50 & 2,60 \\
$30 / 04 / 202 \mathrm{X}$ & 3,75 & 2,70 \\
$15 / 05 / 202 \mathrm{X}$ & 3,80 & 2,80 \\
\hline
\end{tabular}

Swap işlemine ilişkin olarak yapılacak kayıtlar aşağıda görüldüğü gibi olmalıdır.

Sözleşmenin kayıtlara alınması (15/01/202X)

945 Riskten Korunma Amaçlı Türev Finansal Araçlardan Alacaklar 945.122 Swap Faiz Alım İşlemi

945 Riskten Korunma Amaçlı Türev Finansal Araçlardan Alacaklar 945.123 Swap Para Satım İşlemi

947 Riskten Korunma Amaçlı Türev Finansal Araçlardan Borçlar 947.122 Swap Faiz Alım İşlemi

947 Riskten Korunma Amaçlı Türev Finansal Araçlardan Borçlar 947.123 Swap Para Satım İşlemi

31/03/202X tarihinde yapilacak kayitlar;

Bankanın yukarıda yapılan işleme ilişkin olarak yılsonunda almış olduğu ve ödediği faizlerin hesaplarına yansıtılması gereklidir. Bu faizler sebebiyle döviz pozisyonun değişmesinden dolayı vaziyet ve alım- satım hesaplarının kullanılması gerekmektedir. Sözleşmeye konu olan tutar yalnızca alınacak olan ve verilecek olan faizlerin hesaplaması noktasında baz olarak kullanıldığ için nazım kayıta ilişkin değerleme işlemi yapılmasına lüzum yoktur. Bankanın tahsil işlemini gerçekleştirse de gerçekleştirmese de döneme ait olan gelirlerin ve giderlerin yılsonunda sonuç hesaplarına aktarılması gerekmektedir.

Bu bağlamda BB Bankasının DEF Bankasından tahsil etmesi gereken faiz (LİBOR +\%0,25) alacağı; 


\section{AKTAR}

2.000.000 \$ x 0,0375 x 45/360 = 9375\$, (15 Kasım ile 31 Aralık arası 45 Gün) olarak hesaplanmaktadir.

DEF Bankasının BB Bankasına Ödeyeceği sabit (\% 3.25) faiz ise;

2.000.000 \$ x 0,0325 x 45/360 = 8125 \$, (15 Kasım ile 31 Aralık arası 45 Gün) olarak hesaplanmaktadir.

Bu tarihte (31/03/202X tarihinde) gerçekleşen USD/TL (döviz) kurunun 2,60 TL olduğu gözönünde bulundurulduğunda yapılması gereken kayıtlar:

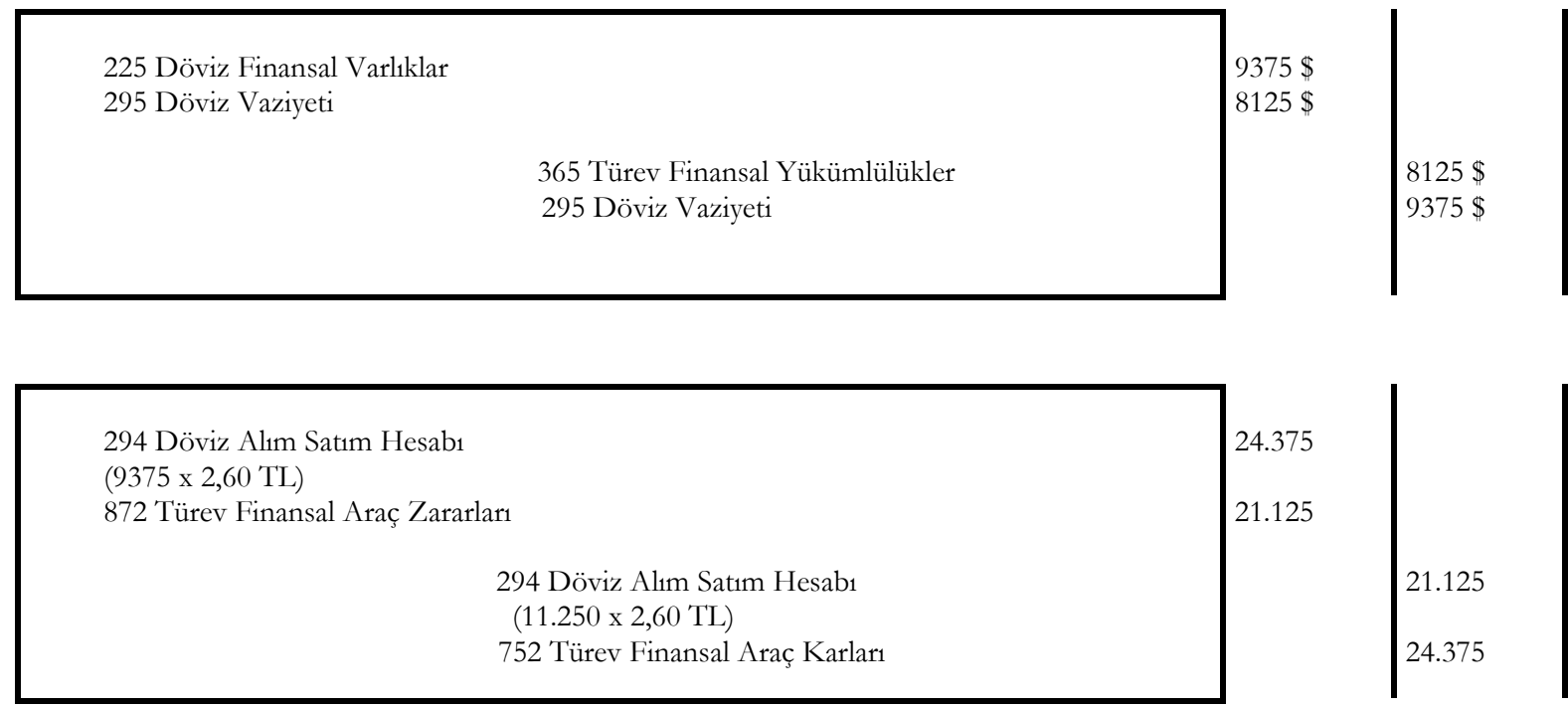

şeklinde olacaktır.

Bankanın yıl sonu itibariyle swap işlemiyle sağlamış olduğu net kazancı (9375 \$ $8125 \$)=1250$ \$ karşılığ1 3250 TL'dir.

Aynı tarihte alınmış olan kredi faizinin artmasından kaynaklı olan ilave gider ise;

2.000.000 \$ x $(0,0450-0,0425) \times 45 / 360=625 \$$ olduğu gözönünde bulundurulduğunda etkinlik olarak 1875/625=\%200 olarak hesaplanmış olup eşik sınırları aştığ1 görülmektedir. Bu koşullar altında net gelir tutarının, öz kaynaklar hesabı altında izlenerek, işlemin bu tarih itibariyle riskten koruma amaçlı muhasebeleştirmeye dair esaslara tabi tutulmayıp hesaplanmış olan net gelir-gider farklarının doğrudan $\mathrm{Kar} /$ Zarar hesaplanna kaydedilmesi gerekli görülmektedir.

31.03.201X tarihinde yapilmas1 gereken kayitlar;

Bankanın yılsonunu takip etmekte olan üç aylık dönemde sözleşme ile sağladığı gelir;

2.000.000\$ x 0,0490 x 90/360 = 24.500\$(1 Ocak ile 31 Mart aras 90 Gün) faiz gideri ise;

$2.000 .000 \$ \times 0,0325 \times 90 / 360=16.250 \$$ dir.

Aynı tarihte netleştirme işlemi yapıldıktan sonra dönem kurunun dikkate alınmasıyla yapılması gereken kay1t; $(24.500 \$-16.250 \$)=8250 \$$

\begin{tabular}{|c|c|c|c|}
\hline 225 Türev Finansal Varlıklar & 295 Döviz Vaziyeti & $8250 \$$ & $8250 \$$ \\
\hline $\begin{array}{l}\text { 294 Döviz Alım Satım Hesabı } \\
(8.250 \times 2,70 \mathrm{TL})\end{array}$ & 752 Türev Finansal Araçlardan Karlar & $22.275 \mathrm{TL}$ & $22.275 \mathrm{TL}$ \\
\hline
\end{tabular}

şeklinde olmalıdır. 


\section{Kapanış kayıtları}

Dönem net gelir - giderlerinin hesaplara aktarılması;

Bir önceki dönemde gerçekleştirilen gelir kaydının ara dönem olması sebebiyle ertesi yıl ters kayıt yapılarak kapatılmış olduğu varsayılırsa 202X yılı içerisinde sözleşmeden kaynaklanmış olan toplam gelir;

2.000.000\$ x 0,0405 x 135/360=30.375\$(1 Ocak ile 15 May1s aras1 135 Gün)

Toplam gider; $2.000 .000 \$$ x 0,0325 x 135/360 = 24.375 $\$$ olarak hesaplanmıştır.

Aradaki fark; $30.375-24.375=6000 \$$

15/05/202X tarihinde yapılacak kayıt ise şu şekildedir:

\begin{tabular}{|l|l|l|}
\hline 225 Türev Finansal Varlıklar & $6000 \$$ & $6000 \$$ \\
\hline $\begin{array}{l}294 \text { Döviz Alım Satım Hesabı } \\
\text { (6000 x 2,80 TL) }\end{array}$ & $16.800 \mathrm{TL}$ & $16.800 \mathrm{TL}$ \\
& 752 Türev Finansal Araçlardan Karlar &
\end{tabular}

Faizin tahsil edilmesi ve yapılan sözleşmenin kayıtlardan çıkartılması;

31/12/202X tarihinde elde edilen gelir; $1250 \$$

Vade sonunda (15/05/202X) gelir; 6000 \$ ise toplam 7250 \$'lik faiz tahsili gerçekleştirilecektir.

025 Yurtdışı Bankalar $7250 \$$

947 Riskten Koruma. Amaçlı Türev Finansal Araçlardan Borçlar 947.122 Swap Faiz Alım İşlemi

947 Riskten Korunma Amaçlı Türev Finansal Araçlardan Borçlar 947.123 Swap Para Satım İşlemi

şeklinde muhasebeleştirilir.

\section{Tartışma, Sonuç ve Öneriler}

Finansal araçlara ilişkin çalışmalarına 1988'de başlayan Uluslararası Muhasebe Standartları Kurulu, bu tarih itibariyle finansal araçlar konusunu devamlı olarak gündemlerinde tutmuşlardır. Kurulun üzerinde görüş birliğine varmış olduğu ve uzun uğtaşlar sonucunda sırayla yayınlamış olduğu bu standartlardan, alacaklar, borçlar, hisse senetleri gibi asıl finansal araçlar olarak tanımlanmış araçların yanı sıra opsiyon sözleşmeleri, vadeli işlem sözleşmeleri, futures, forward, swap ve döviz gibi türev finansal araçlara ilişkin olarak yayımlanan "TMS 32 Finansal Araçlar: Sunum" standardı bahsi geçen finansal araçların finansal tablolara yansımalarının nasıl olacağı ve açıklanması ile ilgili gerekli olan birtakım hükümler içerirken; "TMS 39 Muhasebeleştirme ve Ölçme" standardı; bu standart kapsamında yer alan finansal araçların değerlenmesi ve kaydedilmesine ilişkin hükümlerden oluşmaktadır. 
Ülkelerin gelişmesi için finansal piyasaların gelişim göstermesi büyük önem arz etmektedir. Finansal piyasaların gelişim göstermesi bu piyasalarda kullanılmakta olan araç çeşitliliğinin artırılmasına ve yaygın bir biçimde kullanılmasına bağlıdır. Bahsi geçen ürünler arasında işlem görmekte olduğu piyasalarda en çok göz önünde bulunan araç ise faiz oranı swapı olmuştur. Kullanımda kolaylık sağlaması nedeniyle faiz oranı risklerinin yönetiminde faiz oranı swaplarından yararlanılmıştır.

Ülkemizde daha çok bankalar tarafindan kullanılmakta olan swap sözleşmelerinin kullanım miktarlarının artırılmasının yanında kullanım alanlarının da yaygınlaştırılması gerekmektedir. Ülkemizde türev ürün kullanımıyla ilgili güncel veriler incelendiğinde 2017 yll itibariyle toplam işlem hacminin yaklaşık 2,5 trilyon TL dolaylarında gerçekleștiği görülmektedir. 2,5 trilyon TL'lik bu işlem hacminin yaklaşı olarak \%89,9'unun swap sözleşmeleri, \%6,2'sinin vadeli işlem sözleşmeleri (forward), \%3,8'inin opsiyon sözleşmeleri ve \%0,1'inin futures sözleşmelerinden meydana gelmektedir. Gerçekleștirilen türev ürünler işlem hacminin yaklaşık \%50,1'inin özel sermayeli mevduat bankalarınca, \%38,6'sının yabanc1 sermayeli mevduat bankalarınca, \%7,4'ünün kamu sermayeli mevduat bankalarınca ve \%3,7'sinin kalkınma ve yatırım bankalarınca gerçekleştirildiği gözlenmiştir (Akkaynak ve Yıldırım, 2019, s.25; Saltoğlu, 2019, s.5). Bu veriler kapsamında finansal piyasalarda kullanılmakta olan temel finansal araçların yanı sıra türev araçların da kullanımının artırılması ve yaygınlaştırılması; işletmelerde aktif ve pasif yönetiminde etkinliğin sağlanması, farklı piyasalara erişim ve yeni kredi kullanma maliyetlerinin altında bir maliyetle yeni kaynaklara ulaşım imkanları sunması, üstlenilecek riskleri azaltması ve hatta ortadan kaldırması gibi sayısız faydalar sağlayacağı görüşündeyiz. Bu nedenle swap işlemlerinin yaygınlaştırılması, standartlarının geliştirilmesi, ülkemizde olduğu gibi sadece bankaların değil diğer finansal aktörlerin de bu araç ile finansal riskleri ortadan kaldırma veya en aza indirme gibi avantajlardan yararlanmalarının sağlanması gerektiği kanaatindeyiz.

\section{Etik Beyan}

"Swap Isslemlerinin TMS, BOBI FRS ve VUK Kapsaminda Muhasebelestirilmesi ve Vergilendirilmesi' başlıklı çalışmanın yazım sürecinde bilimsel kurallara, etik ve alıntı kurallarına uyulmuş; toplanan veriler üzerinde herhangi bir tahrifat yapılmamış ve bu çalışma herhangi başka bir akademik yayın ortamına değerlendirme için gönderilmemiştir. Bu araştırmada anket, mülakat gibi etik kurul onayı alınmasını gerektiren bir veri toplama yöntemi kullanılmadığı için etik kurul karanı zorunluluğu taşımamaktadır.

\section{Kaynaklar}

Akay, Hüseyin. (2002). Türev ürünlerden swap işlemleri ve muhasebeleştirme ilkeleri. Mubasebe Bilim Dünyası Dergisi, 4(3), 31-48.

Akkaynak, B. ve Yıldırım, S. (2019). Türev ürünlerin kullanım amaçları:BİST’de bir uygulama. Eræincan Binali Yıldırm Üniversitesi İktisadi ve İdari Bilimler Fakültesi Dergisi. 1(2), 23-33.

Arrkan, A. Naci. (2000). Türev işlemlerin bukuki ve vergisel boyutu. İstanbul: Maliye Hesap Uzmanları Derneği.

Aydın, Erkan. (2002). Swap işlemlerinden sağlanan kazançların gelir vergisi ve kurumlar vergisi uygulamaları açısından niteliği. Yaklaşım Dergisi, 10(109), 217-223.

Aygören, H. ve Kurtcebe, E. (2019). Türev finansal araçların muhasebe standartlarına göre muhasebeleştirilmesi. Muhasebe ve Finansman Dergisi, (86), 1-16.

Bal, Harun. (2001). Uluslararası finansman dıs borç yönetimi ve Türkiye. İstanbul: Türkiye Bankalar Birliği.

Can, C. (2015). Eneriji piyasalarnda türev araçlar ve mubasebesi (Yüksek Lisans Tezi). Okan Üniversitesi, Sosyal Bilimler Enstitüsü, İstanbul.

Ceran, Y. ve Öz, M. (2014). TMS-32, TMS-39 ve TFRS-7, TFRS-9 kapsaminda finansal araçlar: sunum, muhasebeleştirme, ölçüm ve açıllamalar standardına ilişsin bir inceleme. Selçuk Üniversitesi İktisadi ve İdari Bilimler Fakïltesi Sosyal ve Ekonomik. Arasturmalar Dergisi, 14(28), 227-259.

Ceylan, A. (2002). Finansal teknikler. Bursa: Ekin Kitabevi.

Cormick, J. (1993). Currency swaps. Foreign Exchange Yearbook.

Demir, Ş. (2000), Finansal türevler ve vergisel boyutu-II. Yaklaşm Dergisi, 90, 149-156.

Ersan, İ. (1998). Finansal türevler. İstanbul: Literatür Yayınlar1.

Flavell, R. (2002). Swaps and other derivatives. New York: John Wiley \& Sons Ltd.

Kamu Gözetimi, Muhasebe ve Denetim Standartları Kurumu. (2017), Büyük ve Orta Boy İşletmeler İçin Finansal Raporlama Standardi, Ankara.

Keskin, A. D. (2008). Swap işlemi ve bukuki niteliği. Ankara: Yetkin Yayınları.

Kiymetli Şen, İ. ve Özbirecikli, M. (2018). BOBİ FRS’nin muhasebe uygulamalarına getirdiği değişiklikler: BOBİ FRS, TMS/TFRS ve mevcut muhasebe sistemi çerçevesinde bir inceleme. Muhasebe ve Vergi Uygulamalar Dergisi, Özel Say1, 462-484.

Mısırlıŏlu, İ. U. (2008). Türkiye muhasebe standartlarına göre finansal araçların muhasebeleştirilmesi. Mali Cö̋züm Dergisi, 86, 65-81. 
Nurcan, B. (2005). Türev piyasası işlemlerinin vergilendirilmesi ve örnek ülke uygulamalar (Uzmanlık Yeterlilik Tezi). Türkiye Cumhuriyet Merkez Bankası Muhasebe Genel Müdürlüğü, Ankara.

Ocakoğlu, O. (2013). Türev ürünlerin muhasebeleştirilmesi. Mali Çözüm Dergisi, 23(120), 49-63.

Önce, S. (1995). Türev ürünlerin mubasebe sorunlar ve bankalar için mubasebeleștirme șekilleri. Eskişehir: Türkiye Bankalar Birliği Yayını.

Örten, R. ve Örten, İ. (2001). Türev finansal araçlar ve mubasebe uygulamalar. Ankara: Gazi Büro Kitabevi.

Örten, R., Kaval, H. ve Karapınar, A. (2012). Türkiye mubasebe-finansal raporlama standartlar. Ankara: Gazi Kitapevi.

Öz, E. ve Pekşen, F. (2010). Swap işlemleri ve vergilendirilmesi. Vergi Sorunlar Dergisi, 265, 1-13.

Özalp, P. (2003). Türev aras piyasalarmm finansal sistemin işleyişi içindeki rolü: Türkiye' den piyasalara işlerlik kazandirma çalısmalar (Uzmanlık Yeterlilik Tezi), Türkiye Cumhuriyet Merkez Bankası Muhasebe Genel Müdürlügü, Ankara.

Özdemirci, F. (2000). Türev işlemlerin damga dergisi karşısındaki durumu. Vergi Dünyası, 5(225), 137-221.

Özerhan, Y. ve Yanık, S. (2012). TMS/TFRS açklamal ve örnek uygulamal Türkiye mubasebe standartlar Türkiye finansal raporlama standartlar. Ankara: TÜRMOB Yayınları.

Öztürk, V. ve Bal, E. Ç. (2013). Türkiye muhasebe standardı TMS-39 finansal araçlar: muhasebeleştirme ve ölçüm kapsamında türev ürünlerin nakit akış riskinden korunma amaçlı kullanımı: forward örneği. İsletme Araştırmalar Dergisi, 5(2), 123-140.

Öztürk, V. (2001). Swap işlemleri, türk banka işletmelerinde uygulanması ve muhasebeleştirilmesi. Muhasebe ve Denetime Bakıș Dergisi, 5, 117-136.

Sağlam, N., Şengel, S. ve Öztürk, B. (2009). Türkiye mubasebe standartlar uygulaması. Ankara: Maliye ve Hukuk.

Saltoğlu, B. (2019). Türev araçlar, piyasalar ve risk yönetimi. SPL1011 nolu Çalışma Kitabı.

\section{EXTENDED ABSTRACT}

The rapidly changing economic conditions force companies to take more precautions against the risks they are exposed to. This situation makes it more common for companies to use derivative instruments. Derivative instruments are whose prices vary depending on the prices of other instruments and whose value is determined according to the asset subject to the contract within a certain term and at the end. In addition to benefiting from derivative instruments for hedging, companies can also benefit from commercial profit.

The increase in the volume of transactions carried out through derivative instruments has led to a number of problems in the reflection of the financial effects of transactions carried out through these instruments on financial statements. The International Accounting Standards Board has carried out some studies in order to solve all these problems related to recording, evaluation and reporting of transactions carried out with derivative instruments and to ensure integrity in practice and as a result of these studies, TAS 32, TAS 39 and TFRS 7 has entered into force. The purpose of TAS 39; is the determination of principles for the accounting and measurement of financial debts, assets and contracts involving the purchase and sale of non-financial items.

While the provisions regarding the presentation of information on financial instruments are addressed within the scope of TAS 32 Financial Instruments: Presentation, the provisions regarding the disclosures to be made to the public regarding financial instruments are addressed within the scope of TFRS 7 Financial Instruments: Disclosures. According to FRS for LMEs and asset-backed securities; it is measured with its fair value in the first registration and in the following processes. Loan purchase commitments that are among other financial instruments that cannot be fulfilled in cash or become debt instruments when the commitments are fulfilled, are valued at cost. Such commitments are measured at transaction prices, including transaction costs, during initial registration. In later measurements, impairment losses, if any, will be calculated and this amount will be deducted from the cost value. In this context, FRS for LME2 and TAS / TFRS principles are compatible with the valuation of derivative financial instruments.

There is no regulation in the Turkish tax legislation regarding the taxation of the incomes obtained through swap transactions by real persons who are income taxpayers outside the scope of commercial activities. For this reason, it is not possible to evaluate the income obtained from swap transactions within the scope of an income element that can clearly tax. Earnings generated through swap transactions are obtained with cash capital. On the other hand, it is also possible to realize swap transactions as individual investments outside the scope of commercial, agricultural or professional activities. Besides being a subject of discussion, it can also be considered as the income of securities capital. Because the income generated from swap transactions is essentially defined as interest and dividends, and therefore it should 


\section{AKTAR}

be evaluated as securities income. When the decisions made by the council of state are examined, it is seen that the gain from swap transactions is qualified as exchange rate difference, not interest. Therefore, it does not allow the listed transactions to be subject to Income Tax withholding.

The earnings obtained from swap transactions by corporate taxpayers are included in the corporate income and subject to tax without any limitation and without any tax convenience. In case these transactions are carried out as fictitious transactions, the provisions regarding disguised capital regulated in Corporate Tax Law are applied. Accordance with Value Added Tax Act, value-added commercial activities carried out in the context of the delivery of services in Turkey and has been taken under the provisions will be subject to tax. Therefore, transactions related to derivative instruments market carried out within the scope of commercial activities are subject to value added tax. On the other hand, in accordance with aforementioned law, deliveries of foreign currency, gold bullion, stocks, bonds and money are exempted from Value Added Tax. In this context, deliveries of the aforementioned products related to financial derivative instruments are also considered as an exemption from Value Added Tax.

Swap transactions are also carried out with a written contract. Parties of swap transactions change their payments in accordance with the principles and rules they have previously determined with this contract. However, as Capital Market Law, derivatives whose exchanges are being established and traded in the stock exchange are accepted as exemption from stamp tax, agreements regarding swap transactions are considered exempt from stamp tax.

In this study, it is aimed to examine the swap transactions, which are among the derivative products and generally mean the exchange of debts. The taxation and accounting issues of swap transactions are handled within the scope of TAS, FRS for LMEs and Tax Procedure Law and sample applications are included. As a result, recommendations were made within the framework of the example given. Accounting for swap transactions is explained through different sample applications in the context of accounting for currency swaps and interest rate swaps.

Development of financial markets is of great importance for the development of countries. The development of financial markets depends on increasing the variety of vehicles used in these markets and their widespread use. Among the aforementioned products, the most important tool in the markets where they are traded was the interest rate swap. Interest rate swaps have been used in the management of interest rate risks due to their ease of use.

In addition to increasing the amount of use of swap contracts, which are mostly used by banks in our country, the usage areas should also be expanded. Increasing and expanding the use of derivative instruments as well as the basic financial instruments used in financial markets will provide numerous benefits to our country's economy. It should be ensured that swap transactions become widespread in our country, standards are developed, and not only banks but also other financial actors benefit from the advantages such as eliminating or minimizing financial risks with this tool. 